\section{Commentary: A crusade against current pulmonary metastasectomy practice in colorectal cancer patients: Do the con arguments remain after the PulMiCC trial?}

Dirk Van Raemdonck, MD, $\mathrm{PhD},{ }^{\mathrm{a}, \mathrm{b}}$ and

Eric Van Cutsem, MD, $\mathrm{PhD}^{\mathrm{c}, \mathrm{d}}$

In 1095, when Palestinian lands were held by Muslims, Pope Urban II exhorted Christians to reclaim the Holy Sepulchre and other venerated sites. Those who responded wore crosses of cloth on their breasts to identify themselves as soldiers in Christ's army. These consecutive religious and military campaigns in the 11th and 12th centuries to oppose the perceived evil became known in history books as the Crusades. ${ }^{1}$

In an invited expert opinion in this issue of the Journal, Treasure and colleagues ${ }^{2}$ address the remaining uncertainty of the added benefit of offering local therapy for pulmonary metastases to patients with systemic spread of their colorectal cancer. They discuss the outcome of a recently published randomized controlled trial, the PulMiCC trial, ${ }^{3}$ showing no significant survival difference in a limited number of patients comparing pulmonary metastasectomy (PM) versus controls without local treatment (median survival, 3.5 years vs 3.8 years; 5 -year survival, $29.6 \%$ vs $36.4 \%$ ). The estimated unadjusted hazard ratio for death within 5 years, comparing the PM group

\footnotetext{
From the Departments of ${ }^{\mathrm{a}}$ Thoracic Surgery and ${ }^{\mathrm{c}}$ Gastroenterology and Hepatology, Digestive Oncology, University Hospitals Leuven, Leuven, Belgium; and Department of ${ }^{\mathrm{b}}$ Chronic Diseases and Metabolism and ${ }^{\mathrm{d}}$ Oncology, KU Leuven, Leuven, Belgium.

Disclosures: The authors reported no conflicts of interest.

The Journal policy requires editors and reviewers to disclose conflicts of interest and to decline handling or reviewing manuscripts for which they may have a conflict of interest. The editors and reviewers of this article have no conflicts of interest.

Received for publication Feb 2, 2021; revisions received Feb 2, 2021; accepted for publication Feb 3, 2021; available ahead of print Feb 9, 2021.

Address for reprints: Dirk Van Raemdonck, MD, PHD, Department of Thoracic Surgery, University Hospital Gasthuisberg, Herestraat 49, B-3000 Leuven, Belgium (E-mail: dirk.vanraemdonck@uzleuven.be).

J Thorac Cardiovasc Surg 2022;163:491-2

$0022-5223 / \$ 36.00$

Copyright (C) 2021 by The American Association for Thoracic Surgery

https://doi.org/10.1016/j.jtcvs.2021.02.007
}

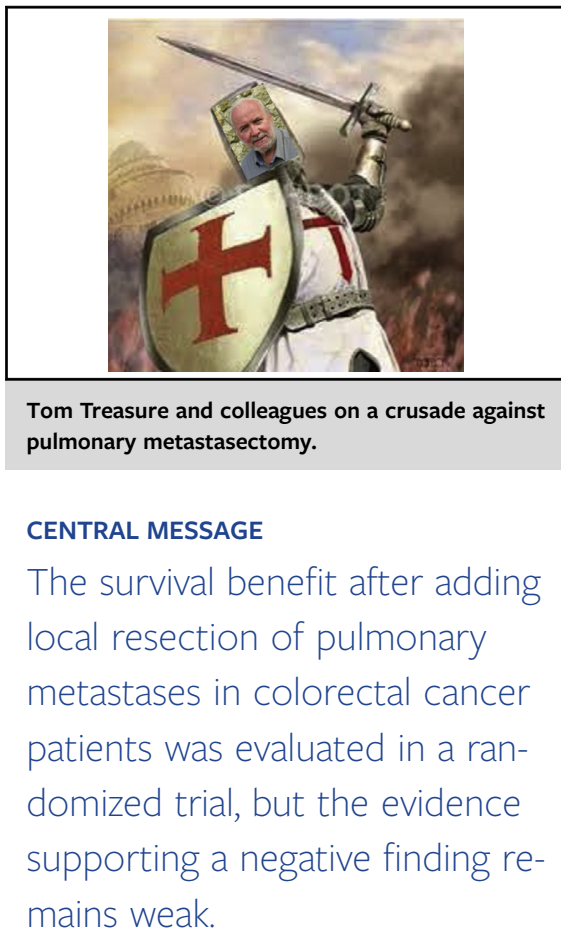

with the control group in the intention-to-treat analysis, was 0.93 . For the "as-treated" analysis, the comparable unadjusted estimated hazard ratio was 0.81 (95\% confidence interval, 0.48-1.37).

Although the power calculation of the trial was done properly based on the available data at that time, the trial was criticized because of the low number of patients included in each group (93 patients were finally randomized out of 512 patients with written informed consent). Critics would argue that the trial closed prematurely and thus was underpowered, and that the data have no validity. The authors of the trial, however, argued that there was equipose between the patients in both groups $(n=46$ and 47), and thus the results are reliable and valid. After reading the discussion in their paper, we conclude that the authors agree that the final question on the added benefit of PM could not be answered by their trial. The authors state that "the results of PulMiCC trial are inconclusive for the main intended outcome, but the finding of a much higher-thanexpected survival of the control patients, compared with what is assumed in nonrandomized (observational) studies, is important." Therefore, the evidence supporting the hypothesis that PM in selected patients does not impact survival remains weak, similar to the statement by many authors from uncontrolled series that PM carries in a survival benefit. ${ }^{4}$ 
We hypothesize that the better-than-expected overall survival in control patients in the PulMiCC is presumably related to better systemic treatment with chemotherapy, targeted therapy, and immunotherapy available during recent years, on top of likely selection of fitter patients with more limited disease. The same holds true for those patients who underwent local treatment. An interesting question that was not addressed in the PulMiCC trial is whether PM as a local treatment modality contributes to a prolonged progression-free survival compared with controls. This could be an argument in favor of continuing PM in patients with colorectal cancer, as stated by Handy and colleagues in a recent expert consensus document by the Society of Thoracic Surgeons Workforce of Evidence Based Surgery: "Statement 10. In colorectal cancer patients, PM can be considered within a multidisciplinary team construct with systemic therapy before or after surgery." ${ }^{5}$ Risk factors for survival guiding selection for surgical treatment are well documented. ${ }^{6}$ Today PM can be accomplished by video-assisted thoracic surgery with short hospitalization and virtually no morbidity and mortality. Besides surgery, other local ablative treatment options are available depending on such clinical aspects as number of lesions, localization, and general status. ${ }^{7,8}$

The authors of the PulMiCC trial should be commended for bringing this important study finding to our attention in an effort to shine more light on the uncertainty in an area of oncologic practice that is very common among thoracic surgeons. Let us be clear: Tom Treasure and Dirk Van Raemdonck are good friends from a long-standing professional relationship when working together on the PM project with the European Society of Thoracic Surgeons. ${ }^{9}$ We carry no swords when arguing with each other. Nevertheless, we disagree on the topic of PM, with pro and con arguments published in a recent editorial. ${ }^{10}$ Indeed, there is no strong positive evidence in favor of resecting PM, in analogy with the lack of evidence from randomized studies for resecting liver metastases or even resection of the primary tumor. It is almost not feasible to perform adequately sized trials in these settings, but indirect evidence has led to the adoption of surgical interventions in the absence of negative outcomes in small underpowered trials. One could paraphrase the quote that there are no randomized trials on jumping out of an airplane with an open parachute instead of keeping it closed, but nonetheless opening it is recommended.

Tom Treasure and colleagues are on a crusade against PM, as witnessed by a track record of articles published in various journals over the last decade. ${ }^{2}$ Nevertheless, we appreciate their continuing efforts to search for more evidence. Their opinion paper will stimulate thoracic surgeons to contemplate their current daily experience-based surgical practice and to participate in trials looking for more scientific evidence.

\section{References}

1. Wikipedia. Crusades. Available at: https://en.wikipedia.org/wiki/Crusades. Accessed January 12, 2021.

2. Treasure T, Dunning J, Williams NR, Macbeth F. Lung metastasectomy for colorectal cancer: the impression of benefit from uncontrolled studies was not supported in a randomized controlled trial. J Thorac Cardiovasc Surg. 2022;163: 486-90.

3. Milosevic M, Edwards J, Tsang D, Dunning J, Shackcloth M, Batchelor T, et al. Pulmonary metastasectomy in colorectal cancer: updated analysis of 93 randomized patients - control survival is much better than previously assumed. Colorectal Dis. 2020;22:1314-24.

4. Pfannschmidt J, Dienemann H, Hoffmann H. Surgical resection of pulmonary metastases from colorectal cancer: a systematic review of published series. Ann Thorac Surg. 2007;84:324-38.

5. Handy JR, Bremner RM, Crocenzi TS, Detterbeck FC, Fernando HC, Fidias PM, et al. Expert consensus document on pulmonary metastasectomy. Ann Thorac Surg. 2019;107:631-49.

6. Gonzalez M, Gervaz P. Risk factors for survival after lung metastasectomy in colorectal cancer patients: systematic review and meta-analysis. Future Oncol. 2015;11(2 Suppl):31-3.

7. Schlijper RC, Grutters JP, Houben R, Dingemans AM, Wildberger JE, Van Raemdonck D, et al. What to choose as radical local treatment for lung metastases from colo-rectal cancer: surgery or radiofrequency ablation? Cancer Treat Rev. 2014;40:60-7.

8. Palma DA, Olson R, Harrow S, Gaede S, Louie AV, Haasbeek C, et al. Stereotactic ablative radiotherapy versus standard of care palliative treatment in patients with oligometastatic cancers (SABR-COMET): a randomised, phase 2, openlabel trial. Lancet. 2019;393:2051-8.

9. Internullo E, Cassivi SD, Van Raemdonck D, Friedel G, Treasure T. Pulmonary metastasectomy: a survey of current practice amongst members of the European Society of Thoracic Surgeons. J Thorac Oncol. 2008;3:1257-66.

10. Van Raemdonck D, Treasure T, Van Cutsem E, Macbeth F. Pulmonary metastasectomy in colorectal cancer: has the randomized controlled trial brought enough reliable evidence to convince believers in metastasectomy to reconsider their oncological practice? Eur J Cardiothorac Surg. 2021;59:517-21. 